\title{
Call Centers Performance An Application of Structuration Theory
}

\author{
Wafa Kort and Jamel Eddine Gharbi
}

Ligue Laboratory, Tunisia

\begin{abstract}
The academic field of individual performance is concerned with a large range of multifaceted questions regarding the prediction of individual performance, the assessment issue, or the enhancement and the keeping of a performance value. Current debates have emerged in call centers context. Based on structuration theory, this paper tries to understand the process that leads to individual performance. A case study based on half structured interviews is made at "Téléperformance". Results show that there are three kinds of determinants: (1) agent features, (2) technological structures and (3) non technological structures shape performance. The relationship between agent features and structures is assumed to be recursive.
\end{abstract}

Key words: Individual performance, Structuration theory, Technology.

\section{Introduction}

Whilst there is a growing body of literature related to individual performance, few attempts have been made to build an integrative framework that explains the individual performance in call centers, especially in relation to technology. Few, few studies even explain the results according to a clear theoretical background. Generally, in the area of individual performance, the proposed models are presented in a deterministic way. They do not explain the motivational forces and processes that explain action and do not take in account the dynamic characteristic of the individual. Thus, they present individual performance as a static phenomenon beyond the time-space dimension. Nevertheless, performance is not stable over time, it is an evolving phenomenon.

Additionally, researches in information system field are fragmented. Generally, researches can be classified into two epistemologies: the positive view and the interpretative view (Orlikowski and Baroudi, 1991). The positivist view is dominant. Positivist information system researches assume that an objective physical and social world exists independent from humans. The researcher is independent from the phenomenon. So the nature of the phenomenon can be explained and apprehended by measure. Hence, according to the methodological stream, studies are generally quantitative with hypothesis testing (Orlikowski and Baroudi, 1991). According to the interpretative view, studies are based on subjective interpretation of phenomenon. The researcher tries to understand a phenomenon using an interpretation of the participants meaning. He belongs to the phenomenon. Here, the social world is viewed as produced and reproduced by actors through the interaction process. (Orlikowski and Baroudi, 1991).

This fragmentation leads to a mass of theories, methodologies and topics (Benbasat and Zmud, 2003). As a consequence, the main topic in the information system field, the IT artifact, is relatively missed. IT artifact should be taken in relationship with the environment in which it is embedded. It is not a neutral

Copyright (C) 2011 Wafa Kort and Jamel Eddine Gharbi. This is an open access article distributed under the Creative Commons Attribution License unported 3.0, which permits unrestricted use, distribution, and reproduction in any medium, provided that original work is properly cited. Contact author: Wafa Kort. Email:wafakort@yahoo.fr 
element. Rather, it is socially constructed (Massey et al, 2001). In this way, Orlikowski and Iacono (2001) make an overview of different IT artifact researches between 1990 and 1999, they state that research in information system is not engaged in its "core subject matter the information technology IT artifact". IT artifact is under theorized. In fact, researches either study the technology environment or the influence of technology on a specific outcome (such as performance) in a deterministic way. Thus, they conceptualize artifact as stable. In this way, the influence of IT artifacts is assumed to be static.

This paper proposes to overload the deterministic conceptualization of IT artifact and individual performance using the structuration theory. In fact, structuration theory conceptualizes the relationships between individuals and structures as an evolving process across the time-space dimension. In the same way, many researches (Jones and Karsten, 2008; Poole and DeSanctis, 2002) state that the structuration theory is an influencing theory in information system research which proposes the integration of different approaches. It allows as a consequence, a novel analysis to explain the role of IT artifact into the organization.

Hence, this paper aims to:

(1) identify the determinants of individual performance in call centers and

(2) to explain the different relationship between these elements using structuration theory as a theoretical background.

To achieve these objectives, an exploratory analysis in a call center "Téléperformance" is made.

This paper will be organized as follows: firstly a literature review about individual performance is presented. Secondly, a presentation of structuration theory is made. The third section deals with research design and methodology. Finally, the third section presents analysis and result discussion.

\section{Individual Performance}

The individual performance is an oldrecent research mainstream. Many researches are interested in this issue, especially, psychologist researchers. Researches sometimes want to predict individual performance, sometimes deal with the assessment issue, or the enhancement and the keeping of a performance value. Nevertheless, all theses attempts topics and interventions that are relevant to individual performance are often scattered in various domains and discussed in isolation (Sonnentag, 2002). The following literature review is interested in performance definitions, dimensions and models.

\section{Performance Definition}

Despite the relevance of individual performance to the organization and the different researches in the field, there is no consensus about a definition. Campbell (1999) states that performance is defined either as outcome or as behavior. This conceptualization is based on Anderson and Oliver (1987) model. Many researches adopt this conceptualization such as Babakus et al, 1996; Babakus et al, 1999; Grant et al, 2002; this is also the case for recent researches such as Johnson and Bharadwaj, 2005).

According to Anderson and Oliver (1987), when outcome performance is the measure of objective performance, behavior approach is more subjective. It concerns the aptitude and the strategies used by salesperson to achieve goals. The behavioral approach gives more freedom to employee than outcome approach because it does not necessitate high manager control. As a consequence, behavior performance is concerned with the relationship that salespersons hold with customers, while, the outcome behavior is concerned with operational task. 


\section{Performance Dimensions}

Performance is seen as a multidimensional construct. Borman and Motowidlo model (1993) makes this assumption. The authors propose a two axes model. The first axe is the job-specific task performance that contributes to transforming raw material into goods and services or to maintaining the organizations technical core. The second axe is about the contextual performance, which includes behaviors that promote the viability of social and organizational network and the psychological climate which embeds technical tasks. Contextual performance is more related to external variable than task performance (Sonnentag and Frese, 2002).

\section{Performance Models}

There are many attempts to build a conceptual framework that relate performance determinants. Unfortunately, up to now there is not enough material in this context. According to the literature, there are three perspectives to study performance:

(1) an individual perspective,

(2) a situational perspective and

(3) a process perspective.

The first perspective emphasizes the individual differences to predict performance. The difference in performance is concerned with the individual difference such as personality, motivation or cognitive style. Accordingly, Campbell et al. (1993) propose a famous model of performance which can be applied to different fields. They define performance as a set of behaviors that are relevant to the goals of the organization. Their model makes a distinction between:

(1) the components,

(2) the determinants and

(3) the antecedents of performance.
The components of performance represent the actual behaviors that constitute performance. The determinants of performance represent the human and technological capacities necessary for individuals to produce these behaviors. The antecedents of performance are the factors that influence differences on each of these capacities (Neal and Griffin, 1999). Later, this model became a starting point of different researches. For example, Neal and Griffin (1999) extend this research adding a situational dimension.

As empirical applications toward this perspective, many researches focus on the study of variables such as personality or motivation. For example, to understand the relationship between personality and job performance, Guion and Gottier (1965) were the first investigators. They conclude that there is not a significant relationship between the two constructs. Later, many Meta-analysis studies show the validity of this relationship (Barrik and Mount; 19932003; Tett et al, 1991).

The second perspective defines the system or situational factors as all the factors beyond the control of individual employees as quality of equipment, availability of resources and difficulty of sales territory and so on (Jawahar, 2005). Such factors have the potential to influence performance directly as well as through effects on task-relevant ability and motivation (Cardy et al., 1995; Peters et al., 1982; Villanova, 1996). Situational factors can enable or constrain performance (Sonnentag and Frese, 2002).

Empirically, many authors have studied the influence of situational factors on performance (Hatcher et al., 1991; Kane, 1997; Peters et al., 1982; Peters et al., 1980; Steel and Mento, 1986). Nevertheless, there are influencing models such as the Blumberg and Pringle model (1982) and the Hackman and Oldham model (1976). Blumberg and Pringle (1982) criticize traditional models of performance and characterize them as missing value. They state that the ability and motivation cannot capture all the determinants of 
performance as such; each variable that affects work performance should be capable of being subsumed under either the dimension of ability or that of motivation. Nevertheless, it is not possible. So, authors advance a new model that replaces motivation and ability with broader concepts that capture more variables. On the other hand, Hackman and Oldham's model focuses on job characteristics as situational factor. They identify five job characteristics: skill variety, task identity, task significance, autonomy and feedback from the job itself. They develop also a task characteristics measure: the JDS. This model is used in many researches to predict performance. In spite of this, Jawahar (2002) claims that there is no model that integrates all situational factors into a single model. According to the literature, each study determines situational factors according to a specific context.

Thus, no individual perspective, even situational can capture all the determinants of performance. Likewise, there is a lack of theoretical research that study the impact of dispositional and situational constructs at the same time.

In this way, Many authors demonstrated that personal factors and situational factors jointly influence performance (Jawahar, 2002; Stajkovic and Luthans, 1998; Kenrick and Funder, 1988; Waldman and Spangler, 1989; Cardy et al., 1995; Carlson, 2000; Waldman, 1994) and suggest studying the joint relationship between personality and situational factors (Kenrick and Funder, 1988). They add that it will be a mistake to separate the two fields.

Finally, the last perspective is less interested in the individual or situational determinants. It focuses rather on the performance process itself and conceptualizes it as an action process. The main questions addressed by this perspective are "How does the performance process look like?" and "What is happening when someone is performing?" (Sonnentag and Frese, 2002, p.13). Such models are based either on the action theory or on the cognitive theory. Cognitive theory is used to explain performance appraisal, decision making, leadership perception and human factors that seek to explain work behavior. More precisely, it is interested in the information processing issue. Besides, Frese and Zapf (1994) propose the action theory to explain the human behavior:

"To establish a general theory of work behavior, Action is a goal oriented behavior, that is organized in specific ways by goals, information integration, plans, and feedback and can be regulated consciously or via routine" (p.271).

Therefore, this paper tries to determine the individual factors, the situational factors, and the process that leads to the individual performance. We propose to explain such a model using structuration theory. In fact, structuration theory offers an opportunity to overload the dualism that characterizes the performance literature.

\section{Structuration Theory}

In his book "the constitution of society: outline of structuration theory" Giddens (1984) claims that his theory is developed in response to the fragmentation of the social field and particularly the organizational field. In this way, the categorization of Burrel and Morgan (1979) is very representative of the field state at this time. Burrel and Morgan (1979) propose to categorize organizational study into four paradigms that are conceptualized through two axes. They opposed subjectivism vs objectivism and radicalism vs regulation. The subjective /objective pole reflects the nature of science, whereas the radical /regulation change reflects the nature of society (Burrel and Morgan, 1979). Every paradigm is a set of different theories that share the main assumptions (Burrel and Morgan, 1979).

Structuration theory rejects the dualism between the different approaches at the ontological, the epistemological and the methodological levels. It highlights a duality. This duality is shown through "the duality of structural" which is the main concept of structuration theory. Giddens 
(1984) claims the system is determined by the interaction between structural and agent rather than by hierarchical relationship. Agent uses social structures to produce actions and these actions are produced and reproduced into the social system. The production and reproduction of actions is by intentional actions that do not always and necessarily lead to intended consequences. Interactions are taking shape in the time-space dimension. Hence, the entity analysis is neither the agency experience independent from context nor the whole society but the set of social practices accomplished and organized across time-space. We are going to make a description of the main concepts:

(1) agent,

(2) duality of structural and

(3) time-space routinization.

\section{Agent}

Actor in the social system is called agent/agency. This nomination is due to the actor characteristics especially their power (Sarasona et al, 2006). Agency is "the capacity to make a difference" (Giddens 1984; p.14). Marshall (2000) defines agency as the human capacity to act intentionally, plan fully and reflexively and in a temporal or biographical mode. Indeed, agency is an assumption about human nature; it's not a variable. Hence, Giddens characterizes agency as "competent". This means that they have tacit and discursive knowledge about the consequences of their own actions and the action of others. They use this knowledge to produce and reproduce action. Giddens assumes that actors have rational actions and reflexive ones. Hence, the interaction of agent with structural is allowed by some capacities: reflexive monitoring, rationalization and motivation that are related according to the stratification model (see fig.1).

\author{
Unacknowledged \\ conditions of action
}

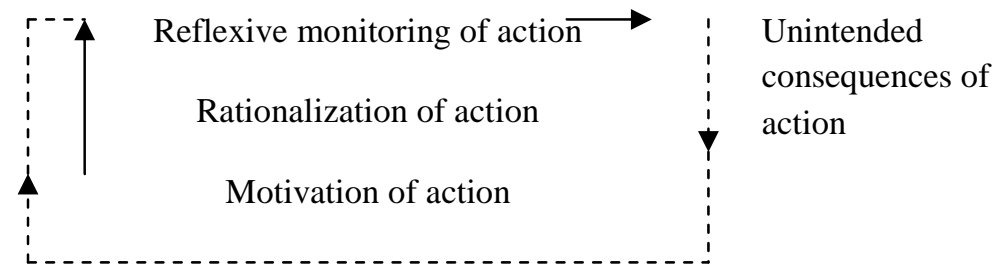

Fig 1. Stratification Model (Adapted from Giddens, 1984, p. 5)

The stratification model deals with the fact that intentional action can lead to unintentional consequences. The unintentional consequences are due to unacknowledged conditions of action. Agents are not always experts about the conditions of interactions. Conditions of interaction may be due to the nature of the time-space constraint. Additionally, agencies are not fully rational (Fuchs, 2002). Rationalization depends on the knowledge-ability. Giddens (1984) states that there are two levels of knowledge: discursive knowledge and practical knowledge. When discursive knowledge is needed to explore new situations, practical knowledge is acquired by the routine of daily interactions. It's rather an unconsciousness phenomenon.

\section{Duality of Structural}

Giddens (1984) uses the concept of structural rather than structure. He claims that he wants to avoid the traditional conceptualization of structure which is rigid and static. Thus, structural is a set of rules and resources engaged in production and reproduction of social system. It exists only in the agent mind. It is not independent from agent. Duality of structural assumes that structural properties are at the same time result and medium of practice which are organized on recursive way. It means that when agent makes a shift into structure, structure influences at the same time agent action. Rules and resources are at the same time product of social interaction and medium. 
This leads to the recreation/reproduction of social system. Social structures and human action are two aspects of the same whole (Chrisalita, 2006). Hence, the reproduction of social system through the duality of structural is called structuration process.

On the other hand, to achieve individual interaction, agent is influenced by structural properties which define prior interactions. This is what Giddens calls "dimensions of structural". These dimensions state that the social system is governed by a need for sense (significance), an importance of hierarchy (domination) and rights and obligations (legitimation). Theses dimensions are related to interaction through modalities. Agents are producing structures through modalities. Giddens (1984) defines modality as linking agent competencies to structural elements. Modality dimensions are interpretive schemes, facilities, and norms respectively. Whereas interaction dimensions are respectively communication, power, and sanction.

\section{Time-space, Routinization}

The previous purposes about agent and structural lead us to talk about the concept of temporality and routine. According to structuration theory the recursive relationship between the reflexivity of agent and structural cannot occur independently from time-space. The action of agent is not dependent merely on their characteristics as competency or capability. It also depends on context. Giddens (1984) states that the study of the time-space dimension is a main issue in social science, we do not have the choice to leave this dimension. Time-space is not just a passive dimension of social system and independent from action. It is rather an action maker element. Giddens (1984, p 377) describes time space as "the stretching of social systems across time-space, on the basis of mechanisms of social and system integration". As structural properties are resulting from the reproduction of social practices across time-space dimensions, the positioning of actors within the social time-space and in respect to rules allows the routinization of actions. Thus, routine constitutes "the habitual, taken-for-granted character of the vast bulk of the activities of day-to-day social life."(Giddens, 1984, p.376).

\section{Structuration Theory and Information System Research}

In its original formulation, Giddens did not pay a great attention to technology and information system. Poole and DeSanctis (2002) claim that structuration theory is concerned with the nature of social system and does not include consideration of technology or the influence of technology on social life. Nonetheless, its appeal to IS lies in its focus on structural and on processes by which structures are used and modified over time. Hence, the aim of structuration theory in the IS field is to provide theoretical approach that helps the understanding of the interaction of user and information technology, the implications of these interactions and the way to control their consequences (Pozzebon and Pinsonneault, 2005). The big difference between structuration theory as formulated by Giddens (1984) and its use on MIS field is about the conceptualization of structural. While Giddens asserts that structural is embedded in agent mind, information system researches assume that structural is independent from agent.

Jones and Karsten (2008) claim we should give technology an existence separate from the practices of social actors and independent from action. Ontologically, a structural that resides in a real, material, artifact would also seem clearly distinct from one that exists only when instantiated in the practices of social actors. So, as information technology has advanced to become more communication-based and collaborative, the field's concern with the structuring properties of technology has persisted (Poole and DeSanctis, 2002). Accordingly, Orlikowski and Robey (1991) try to define technology according to structuration theory. They suppose that it is both a product and a determinant of action simultaneously. They posit that the duality of technology is expressed in its 
constituted nature and constitutive role. Hence, technology is " a social product of subjective human action within specific structural and cultural contexts" and it is "simultaneously an objective set of rules and resources involved in mediating human action and hence contributing to the creation, recreation, and transformation of these contexts" (Orlikowski and Robey, 1991, p11).

The application of structuration into IS field takes primarily three forms:

1) studies that use some concepts of structuration theory

2) studies using emerged theories, and

3) studies that combine structuration theory with other theories.

The first group is generally case studies that interpret the finding using concepts emerging from structuration theory such as structural properties (significance, domination, and legitimation). According to this perspective, we cite Rose and Lewis (2001) that use structuration theory to explain the role of IT artifacts in the production and the socialization of organizational knowledge. Rossi and Zamarian (2006) use structuration theory to explain information system development. The second group are studies based on adaptive structuration theory (DeSanctis and Poole, 1994) or structurational model of technology (Orlikowski, 1992). The last category is related to studies which combine structuration theory with other theories as actor network theory (Brooks and Atkinson 2004; Brooks et al, 2008) or critical realism theory (Bhaskar, 1979; and Archer, 1982). The main assumption of critical realism is the separation between agent and structural. It is gone beyond the conflation between agents and structural proposed by Giddens. In this way, technology can be conceptualized as structural.

In their Meta-analysis, Pozzebon and Pinsonneault (2000) claim that $25 \%$ of the article use adaptive structuration framework. Approximately $75 \%$ of the selected articles combined Giddens' structuration theory with theories of other authors such as Foucault, Weick and Orlikowski. Besides, through an overview of the different theories that focus on structuration theory, Jones and Karsten (2008) state that adaptive structuration theory has been an important influence on structurational IS research, with about 20 percent of the papers covered in this review adopting it in one way or another. Nevertheless, AST is a contingent model; it is far from the duality that Giddens adopt (Rose, 2001).

\section{Research Design and Methodology}

To determine the factors that influence individual performance in call centers, an exploratory analysis in call centers is made. Generally, the famous methods used in qualitative analysis are: interviews, focus group and observation (Thiétart and Roll, 1999). This research is based on interviews. Interviews are chosen for two reasons. Firstly, interviews provide a great amount of information. Secondly, this research focuses on individual level; we try to determine the factors which influence performance at the individual level. Hence, the statements of individuals are the most required.

An interview guide is used. This guide is composed from some questions to encourage participants to talk freely. "How can you describe a phone operator's good performance?" or "Which factors influence phone operator performance?" are examples of these questions. Although, the general structure of the interview focuses on specific information, the running of the conversation was not rigid. Participants are given the freedom to talk about different topics. The "Téléperformance" company is chosen to make the study for two reasons. Firstly, it is the largest call center in Tunisia which employs approximately 4000 persons. In addition to that, it is the world leader in the call center field. ${ }^{1}$ "Téléperformance" is an offshore French company.

\footnotetext{
${ }^{1}$ http://www.teleperformance-tunisie.com/
} 
Firstly, participants, recruited for the study, were contacted by friends. Many of them refuse to do the interview because it necessitates one hour approximately, for this reason the interviews may not be enacted at work. In fact, the working conditions do not allow making the interview in the workplace particularly because lunch break is just one hour. Other participants were contacted via the web site "Facebook", especially via the following groups: Téléperformance Tunisie (STT), Teleperformance Tunisie, Téléperformance Charguia2, Le syndicat de Téléperformance. The interviews were recorded via the "MP5" recorder. This technology allows setting the recorder in the personal computer. 19 interviews were made. Three of them were deleted from the analysis. In fact, two of them were badly recorded. As for the third one, it was deleted because the participant works in "Daxon" where only one application is used. As Taylor and Bain (1999) claim, there are many operations which are low on technical component but classified as call centers. These operations should be rather described as customer service centers or customer satisfaction centers. Thus, in this study we are rather interested in operations based on high technology. Hence, technology presents many applications and allows information processing and decision making. Therefore, participants work on the following operation: Numéricable, SFR, Orange and Bell Canada. Finally, 16 usable interviews were obtained. The sample is composed from $43,75 \%$ female and 56,25\% male.. Work duration in call center varies from 5 months to 6 years. We did not notice that family status of participants has altered answers.

The content analysis is selected as an encoding method. This method focuses on the repetition of text analysis unit (Thiétart and Roll, 1999). The unit may be a word, a set of words, a sentence, a piece of sentence, one paragraph or many (Weber, 1990). These units should refer to the same idea generated by the interviewee. Thus, the text is cut according to the unit analysis chosen previously by the researcher. Analysis units are later organized according to categories (Thiétart and Roll, 1999). In this way, theme and thematic theme are found (Haberman and Miles 1994). When the first three interviews were coded we gave them to a colleague for a trial encoding. The aim is to have an encoding reliability (Weber, 1990). This reliability rate should be $80 \%$. It presents the rate of agreement between the researchers to encoding a text share. The result of the content analysis leads to find 56 determinants of individual performance (appendix1).

\section{Analysis and Discussion}

The main criticism addressed to structuration theory is the conflation between structure and agent (Rose, 1998; Layder, 2006; loyal, 2003). This problem is not elucidated by Giddens. On the contrary, he addresses the issue by insisting on the difference that exists between structure and social system (Giddens, 1989). Structure has a virtual existence, and system refers to the patterning of social interaction and social relationships across time and space. When Giddens assumes that structure depends on agent he omits the fact that a given social system exists before and after the individual. This distinction is very sensitive; it takes the problem to a different direction, without providing any resolution. To go beyond this main criticism, we assume that "The structural is independent of agent". This assumption is a great difference between the definition of structural in information system and its original formulation in structuration theory. If structural exists only in the agent mind, technology cannot be considered as structural. Because technology exists independent from agent, it has a physical existence. Giddens (1984) assumes that resource can be independent when he talks about allocative resource. Allocative resources are supposed to have physical existence as artifact. Giddens (1984) posits that these resources are controlled by human power, but he did not mention the possibility of their independent change. But the structural (as technology) can change independently of agent. For example in the case of call center, phone operators do not work with 
the same tools and rules during their work. Tools are changed and evaluated independent from phone operator's use. This assumption does not alter the definition of structural as a set of rule and resource that constraint and enable the action. Nonetheless, it makes a fusion between structural properties and structure. In keeping with, we follow many researches such as Archer (2010). More to this point Giddens (1984) states that rules do not have the same importance for each structure. Therefore, it is important to separate the structure from the agent to assess these differences. Structure and agency should be considered as two complementary poles (Thompson, 1989), rather than as two poles of the same coin as suggested by Giddens.

As a consequence, the found items are classified according to structuration theory into three groups as in the following:
1. Determinants related to agents (e.g. extrinsic motivation, under estimation);

2. Determinant related to technology (e.g. tools, technology equipment);

3. Determinants not related to technology (e.g. material and suppliers, supervisor).

The first group is composed of agent features, the second group is called technological structures, and the third group is called the non technological structures. This classification is presented in the second appendix.

Giddens (1984) states the duality of structural that occurs between the reflexive monitoring of agent and structures. Hence, in this case, the duality of structural occurs between the reflexive monitoring of agent and technological and non technological structures. Thus, these relationships can be presented in the following scheme.

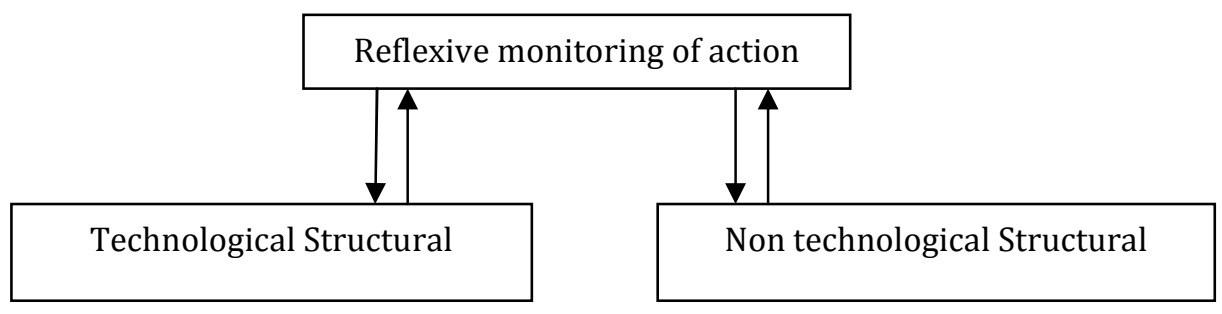

Fig 2. Agent-structure Relationship (adapted from Giddens, 1984)

According to the interpretation of the main concept of performance in this study, the following explanation is advanced. Structuration theory assumes that the interaction between agency and structural leads to consequences: intended and unintended consequences. Unintended consequence of action may be for example "bad performance" although the phone operator tries a bit harder to perform. In fact, performance appraisals can be opposed as "satisfy customer with speed call". As a consequence, the phone operator should sacrifice one condition in return for another. This leads to unintended consequence of action. More to this point a distinction between performance and result of performance should be understood in the aim to grasp the position of individual performance in structuration theory. Campbell (1990) argues that "performance is not the consequence(s) or result(s) of action; it is the action itself" (p.704). On the other hand, he defines effectiveness as "the evaluation of the results of performance" (p.715). It is something that can be controlled and measured. In keeping with this, performance indicators in call center fit with this definition. Effectiveness is also an addition of action plus an error. The error can be assimilated to the unintended consequence of action. Accordingly, we propose that the action is the latent attribute of performance and the consequence of action is the manifest or parent attribute of performance or keeping with Campbell (1990) is the effectiveness. In summary, using structuration terms, performance is composed by action and 
consequence of action that can be also called effectiveness.
As a consequence the previous figure can be transformed as follows.

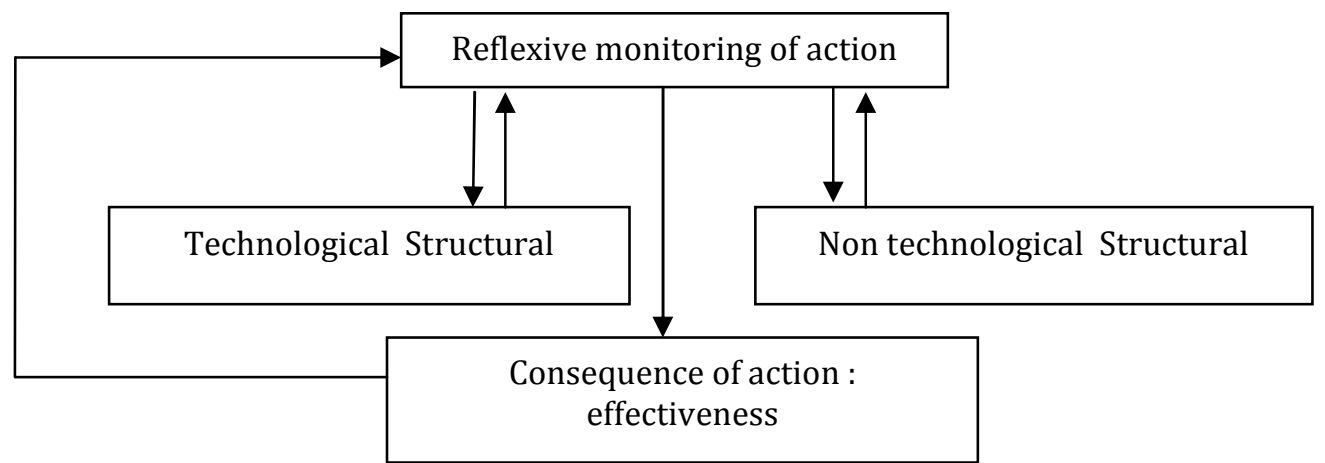

Fig 3. Performance Process

Therefore, structuration theory justifies relationships between the performance determinants. In keeping with the above analysis, the relationship between technological structural and agent is assumed to be recursive. This leads to an overloading of the deterministic presentation of IT artifact (technological structures). Indeed, the agent is related to non technological structures too such as social structures. We cite the relationship with supervisor as an example of social structures. This leads to fill in the second theoretical gap that IT artifact is undertheorized and is not assessed into a social context. Therefore, performance is the result of the interaction between the reflexive monitoring of action and the structures. Indeed, it is related to agency capability and knowledge-ability. The performance evolves across the time-space dimension and the routinization process. As claimed by Giddens (1984) the consequence of action can be intended or unintended. In this way, performance can also be an unintentional result. For example, unintended consequences of action may be for example "bad performance" although the phone operator tries a bit harder to perform. In fact, performance appraisal can be opposed as "satisfy customer with speed call". As a consequence, phone operator should sacrifice one condition in return for another. This leads to unintended consequence of action. The intended and unintended consequences of action remain the controversy that exists between the different performance ratings in call center.

The results of this study are different from the performance models cited in the first section. The previous models assume that factors such as relationship with supervisor, equipment, and environment directly influence the performance. Nevertheless, they do not study how can the reflexive monitoring of action influence structures.

\section{Conclusion}

The aims of this research are to identify the determinants of individual performance in call center context and an interpretation of different relationships using the structuration theory. An exploratory analysis is made through half structured interview in "Téléperformance". The analysis identifies structures and agency features as determinants of performance. There are two structures: technological structural and non technological structural. The IT artifact is assimilated to the technological structures. Thus, IT artifact is related to social structure. It is conceptualized in a dynamic way, that is the relationship between agency and structural is recursive.

Among the research limits; investigation is made only in one company. Thus, a generalization of result is not possible. We are not yet near to build a framework. 
Future steps should extend this research to other sites. Future steps should test selected structures and selected agent features among all found determinants. Sich studies should be made using a longitudinal study to assess the evolution across time. The cross sectional studies cannot take into account the evolution of the process. The result of such analysis will be far from the dynamic conceptualization of social system stated by Giddens.

\section{References}

Anderson, E. \& Oliver, R. L. (1987). "Perspectives on Behavior-Based versus Outcome-Based Salesforce Control Systems," The Journal of Marketing, 51(4), 76-88.

Archer, M. S. (2010). "Morphogenesis Versus Structuration: On Combining Structure and Action," British Journal of Sociology, pp. 225-252.

Babakus, E., Cravens, D. W., Johnston, M. \& Moncrief, W. C. (1999). "The Role of Emotional Exhaustion in Sales Force Attitude and Behavior Relationships," Journal of the Academy of Marketing Science, 27, 58.

Benbasat, I. \& Zmud, R. W. (2003). "The Identity Crisis within the IS Discipline: Defining and Communicating the Discipline's Core Properties," MIS Quarterly, 27(2), 183-194.

Borman, W. C. \& Motowidlo, S. J. (1997). "Task Performance and Contextual Performance: The Meaning for Personnel Selection Research," Human Performance, 10, 99-109.

Brooks, L., Atkinson, C. \& Wainwright, D. (2008). "Adapting Structuration Theory to Understand the Role of Reflexivity: Problematization, Clinical Audit and Information Systems," International Journal of Information Management, 28, 453-460.

Burrell, G. \& Morgan, G. (1979). "Sociological Paradigms and Organisational Analysis," Heinemann, London.
Campbell, J. P. (1999). 'The Definition and Measurement of Performance in the New Age,' In D. R. Ilgen \& E. D. Pulakos (Eds.), The changing nature of performance. Implications for staffing, motivation, and development (pp. 399-429), Jossey-Bass, San Francisco.

Campbell, J. P., McCloy, R. A., Oppler, S. H. \& Sager, C. E. (1993). 'A Theory of Performance,' In E. Schmitt, W. C. Borman, \& Associates (Eds.), Personnel selection in organizations (pp. 35-70), Jossey-Bass, San Francisco.

Cardy, R. L., Dobbins, G. H. \& Carson, K. P. (1995). "TQM and HRM: Improving Performance Appraisal Research, Theory and Practice," Canadian Journal of Administrative Sciences, 12(2), 106-115.

Carlson, K. D. (2000). 'A Model of the Determinants of Performance Outcomes,' Paper presented at the Annual Academy of Management Meetings, Toronto, Canada.

De Vaujany, F.-X. (2008). "Capturing Reflexivity Modes in IS: A Critical Realist Approach," Information and Organization, $18,51-72$.

DeSanctic, G. \& Poole, M. S. (1994). "Capturing the Complexity in Advanced Technology Use: Adaptive Structuration Theory," Organization science, 5 (2).

Frese, M. \& Zapf, D. (1994). "Action as the Core of Work Psychology: A German Approach," In H. C. Triandis, M. D. Dunnette, \& L. M. Hough (Eds.), Handbook of industrial and organizational psychology (2nd edn, Vol. 4, pp. 271-340), Consulting Psychologists Press, Palo Alto, CA.

Fuchs, C. (2002). "Some Implications of Anthony Giddens: Works for a Theory of Social Self-Organization," Emergence, 4(3), 7-35.

Giddens, A. (1984). 'The Constitution of Society: Outline of Structuration Theory,' Politic press, Cambridge

Giddens, A. (1989). "A Reply to My Critics", In Social theory of modern societies: Anthony Giddens and his critics, D. Held 
and J. B. Thompson, pp. 249-305. Cambridge, Cambridge University Press.

Guion,R. M. \& Gottier, R. F. (1965). "Validity of Personality Measures in Personnel Selection," Personnel Psychology, 18, 135164.

Grant, K., Cravens, D. W., Low, G. S. \& Moncrief, W. C. (2001). "The Role of Satisfaction with Territory Design on the Motivation, Attitudes, and Work Outcomes of Salespeople," Journal of the Academy of Marketing Science, 29, 165.

Haberman, M. A. \& Miles, M. (1994). Qualitative Data Analysis, Sage publication, Second Edition, London.

Hackman, J. R. \& Oldham, G. R. (1976). "Motivation through the Design of Work: Test of a Theory," Organizational Behavior and Human Performance, 16, 250-279.

Jawahar, I. M. (2002). "The Influence of Dispositional Factors and Situational Constraints on End User Performance: A Replication and Extension," Journal of End User Computing, 14(4), 17-36.

Jawahar, I. M. (2005). “Do Raters Consider the Influence of Situational Factors on Observed Performance When Evaluating Performance? Evidence from Three Experiments," Group Organization Management, 30, 6.

Jones, M. R. \& Karsten, H. (2008). “Giddens Structuration Theory and Information Systems Research," MIS Quarterly, 32(1), 127-157.

Layder, D. (2006). "Understanding Social Theory," Sage Publications, London Thousand Oaks New Delhi, Second edition.

Loyal, S. (2003). 'The Sociology of Anthony Giddens,' Pluto Press, London Sterling Virginia.

Marshall, V. W. (2000). "Agency, Structure, and the Life Course in the Era of Reflexive Modernization," A symposium on "The Life Course in the 21st Century", American
Sociological Association meetings, August, Washington DC.

Neal, A. \& Griffin, M. A. (1999). “Developing a Model of Individual Performance for Human Resource Management," Asia Pacific Journal of Human Resources, 37.

Orlikowski, W. J. (1992). "The Duality of Technology: Rethinking the Concept of Technology in Organizations," Organization Science Focused Issue: Management of Technology, 3(3), 398-42.

Orlikowski, W. J. \& Baroudi, J. J. (1991). "Studying Information Technology in Organizations: Research Approaches and Assumptions," Information Systems Research, 2(1), 1-28.

Orlikowski, W. J. \& lacono, C. S. (2001). "Research Commentary Desperately Seeking the 'IT' in IT Research: A Call to Theorizing the IT Artifact," Information Systems Research,12(2), 121-134.

Orlikowski, W. J. \& Robey, D. (1991). "Information Technology and the Structuring of Organizations," Information Systems Research, 2(2), 143-169.

Poole, M. S. \& DeSanctis, G. (2002).'Structuration Theory in Information Systems Research: Methods and Controversies,' The Handbook for Information Systems Research (Michael E. Whitman \& Amy B. Woszczynski, Editors).

Pozzebon, M. \& Pinsonneault, A. (2000). "The Structuration Theory in IS: Usage Patterns and Methodological Issues," Cahier du GReSI no 00-05.

Pozzebon, M. \& Pinsonneault, A. (2005). "Challenges in Conducting Empirical Work Using Structuration Theory: Learning from IT Research," Organization Studies, 26(9), 1353-1376.

Rose, J. \& Lewis, P. (2001). "Using Structuration Theory in Action Research: An Intranet Development Project," In: Russo, L and Fitzgerald, B and DeGross, JI, Realigning Research and Practice in Information Systems Development: the 
Social and Organisational Perspective. pp. 273-296, Kluwer Academic Publishers, Dordrecht.

Rose, R. (2001). "Structuration Theory and Information System Development Frameworks for Practice," In Proc of the 9th European Conference on Information Systems, Bled.

Rossi, A. \& Zamarian, M. (2006). "Designing, Producing and Using Artifacts in the Structuration of Firm Knowledge: Evidence from Proprietary and Open Processes of Software Development," ROCK Working Papers, XXII EGOS Colloquium, Bergen

Sarason, Y., Dean, T. \& Dillard, J. F. (2006). "Entrepreneurship as the Nexus of Individual and Opportunity: A Structuration View," Journal of Business Venturing, 21, 286-305.

Stajkovic, A. D. \& Luthans, F. (1998). "Selfefficacy and Work-Related Performance: A meta-analysis," Psychological Bulletin, 124(2), 240-261.

Sonnentag, S. (2002). Psychological Management of Individual Performance, John Wiley \& Sons, LTD, Chichester: UK.
Sonnentag, S. \& Frese, M. (2002). "Performance Concepts and Performance Theory," In Psychological Management of Individual Performance, John Wiley \& Sons, LTD. Chichester: UK.

Taylor, P. \& Bain, P. (1999). “An Assembly Line in the Head: Work and Employee Relations in the Call Centre," Industrials Relations Journal, 30(2), 101-107.

Thompson, M. P. A. (2004). "Confessions of an IS Consultant or the Limitations of Structuration Theory," Cambridge Research Papers in Management Studies, 1.

Waldman, D. A. (1994). "The Contributions of Total Quality Management to A Theory of Work Performance," Academy of Management Review, 19(3), 510-536.

Waldman, D. A. \& Spangler, W. D. (1989). "Putting together the Pieces: A Closer Look at the Determinants of Job Performance," Human Performance, 2, 29-59. 


\section{Appendix 1. Performance Determinants}

\begin{tabular}{|c|}
\hline 1. Agent value and behavior \\
\hline 2. $\quad$ Anxiety \\
\hline 3. $\quad$ Cognitive style \\
\hline 4. $\quad$ Corrupt relationship \\
\hline 5. Customer type \\
\hline 6. $\quad$ Discrimination \\
\hline 7. $\quad$ Experience \\
\hline 8. $\quad$ Familiarity with technology \\
\hline 9. Feeling enslaved \\
\hline 10. Individual culture \\
\hline 11. Initial skill \\
\hline 12. Involvement \\
\hline 13. Lay off anxiety \\
\hline 14. Management of phone operator \\
\hline 15. Material and supplies \\
\hline 16. Mood \\
\hline 17. Motivation/ Extrinsic motivation \\
\hline 18. Motivation/according to gratefulness \\
\hline 19. Motivation/intrinsic motivation \\
\hline 20. Organization structure \\
\hline 21. Overwork \\
\hline 22. Perception of work stability \\
\hline 23. Performance appraisal \\
\hline 24. Personal condition \\
\hline 25. Personal status \\
\hline 26. Personality \\
\hline 27. phone operator lifecycle \\
\hline 28. Product Knowledge \\
\hline 29. Product type (job) \\
\hline 30. Relationship with co-workers \\
\hline 31. Relationship with supervisor \\
\hline 32. relationship with the look-out staff \\
\hline 33. Relationship with top managers \\
\hline 34. Role perception \\
\hline 35. Routine \\
\hline 36. Satisfaction \\
\hline 37. skills required \\
\hline 38. Socio-demographic factors \\
\hline 39. Stress coping \\
\hline 40. Stress/overwork \\
\hline 41. Stress/role ambiguity \\
\hline 42. Stress/role conflict \\
\hline 43. Stress/stress according to work condition \\
\hline 44. Stress/stress according to work tasks \\
\hline 45. Stress/stress caused by managers \\
\hline 46. Stress/stress caused by personal condition \\
\hline 47. Stress/stress caused by the perception future and stability \\
\hline 48. Task characteristics (comple xity) \\
\hline 49. Technology equipment \\
\hline 50. Tools \\
\hline 51. under estimation \\
\hline 52. Work condition/ center location \\
\hline 53. Work condition/ state of platform \\
\hline 54. Work condition/ transport \\
\hline 55. Work condition/planning \\
\hline 56. Work environment \\
\hline
\end{tabular}




\section{Appendix 2}

\begin{tabular}{|ll|}
\hline Agent feature \\
\hline 1. & Cognitive style \\
\hline 2. & Familiarity with technology \\
\hline 3. & Feeling enslaved \\
\hline 4. & Individual culture \\
\hline 5. & Initial skills \\
\hline 6. & Involvement \\
\hline 7. & Lay off anxiety \\
\hline 8. & Mood \\
\hline 9. Motivation/ Extrinsic motivation \\
\hline 10. Motivation/according to gratefulness \\
\hline 11. Motivation/intrinsic motivation \\
\hline 12. Perception of work stability \\
\hline 13. Personal condition \\
\hline 14. Personal statue \\
\hline 15. Personality \\
\hline 16. phone operator lifecycle \\
\hline 17. Role perception \\
\hline 18. Satisfaction \\
\hline 19. Skill required \\
\hline 20. Socio-demographic factor \\
\hline 21. Stress coping \\
\hline 22. Stress coping \\
\hline 23. Stress/stress caused by personal condition \\
\hline 24. under estimation \\
\hline
\end{tabular}

\begin{tabular}{|l|}
\hline \multicolumn{1}{|c|}{ Technological structures } \\
\hline 1.Tools \\
\hline 2. Technology equipment \\
\hline
\end{tabular}




\begin{tabular}{|ll|}
\hline Non technological structures \\
\hline 1. & Corrupt relationship \\
\hline 2. & Customer type \\
\hline 3. & Discrimination \\
\hline 4. & Management of phone operator \\
\hline 5. & Material and supplies \\
\hline 6. & Organization structure \\
\hline 7. & Overwork \\
\hline 8. & Performance appraisal \\
\hline 9. & Product Knowledge \\
\hline 10. & Product type (job) \\
\hline 11. & Relationship with coworkers \\
\hline 12. relationship with lay-out staff \\
\hline 13. Relationship with supervisor \\
\hline 14. Relationship with top managers \\
\hline 15. routine \\
\hline 16. Stress/overwork \\
\hline 17. Stress/role ambiguity \\
\hline 18. Stress/role conflict \\
\hline 19. Stress/stress according to work condition \\
\hline 20. Stress/stress according to work tasks \\
\hline 21. Stress/stress caused by manager \\
\hline 22. Stress/stress caused by the perception \\
\hline 23. Task characteristics (complexity) \\
\hline 24. Work condition/ center place \\
\hline 25. Work condition/ state of platform \\
\hline 26. Work condition/ transport \\
\hline 27. Work condition/planning \\
\hline 28. Work environment \\
\hline
\end{tabular}

